EPiC Series in Engineering
Volume 3, 2018, Pages 1435-1443
HIC 2018. 13th International
Conference on Hydroinformatics

\title{
Land Use/Land Cover Changes Monitoring and Analysis of Dubai Emirate, UAE Using Multi- Temporal Remote Sensing Data
}

\author{
Mohamed Mostafa Mohamed ${ }^{1}$ and Samy Ismail Elmahdy ${ }^{1}$ \\ ${ }^{1}$ Civil and Environmental Engineering Department, College of Engineering United Arab Emirates \\ University,P.O. Box 15551, Al-Ain, United Arab Emirates. \\ m.mohamed@uaeu.ac.ae, samy@uaeu.ac.ae
}

\begin{abstract}
Dubai is a rapidly urbanizing emirate with land development succeeding at a fast pace. The present study aims to develop a low-cost classifier based on the spectral angle mapper (SAM) and image difference (ID) algorithms. The proposed approach was developed in order to improve Land use/ Land cover (LULC) classification maps for the purpose of monitoring and analysing LULC change during the period from 2000 to 2015 for the Emirate of Dubai. The approach starts by collecting 320 training samples from high resolution images such as QuickBird with a spatial resolution of $60 \mathrm{~cm}$ followed by applying a $3 \times 3$ spatial convulsion filter, majority/ minority analysis, sieving classes and clump map of the produced LULC maps. After that, the accuracy of the maps were assigned using confusion matrix. The accuracy assessment demonstrated that the targeted 2000, 2005,2010 and 2015 LULC maps have $88.125 \%, 89.069 \%, 90.122 \%$ and $96.096 \%$ accuracy, respectively. The results exhibited that the built-up areas increased by $233.72 \mathrm{~km}^{2}(5.81 \%)$ from 2000 to 2005 and keeps to increase even up and till the present time. The results also showed that the changes in the periods 2000-2005 and 2010-2015 confirmed that net vegetation area loses were more obvious from 2005 to 2005 than from 2010 to 2015 , reducing from $47.618 \mathrm{~km}^{2}$ to $40,820 \mathrm{~km}^{2}$, respectively. This study is of great help to urban planners and decision makers.
\end{abstract}

\section{Introduction}

Remote sensing images represent a valuable spatial and temporal information data source to monitor dynamics of land use/land cover (LULC) changes and predict their impact on any environmental issues over a regional scale. Multi-sources of Landsat images with a temporal resolution of five years enable more reliable exploration applications than was previously the case. Especially in poorly accessible arid and semiarid regions. Landsat images are widely used as the main data sets to both classify LULC and detect changes on a worldwide basis. Several pixel-based change detection methods, including image difference, image rationing, image regression and change vector analysis have been developed for rapid detection of changes in urban areas using remote sensing data 
(Griffiths 1988; Saksa et al. 2003; Coppin et al. 2004; Lu et al. 2004). Other studies have been applied to develop the SAM algorithm. Cho et al. (2009) assessed the impact of using multiple endmembers on the classification performance and vegetation types discrimination. An expert system was applied to the SAM algorithm by refining, reclassifying and reducing errors in initial classified outputs. The SAM algorithm was tested for mapping the LULC characteristics using a Hyperion and/or hyperspectral images (Rashmi et al., 2014). Unfortunately, spatial information derived from hyperspectral data makes LULC classification hard to resolve and requires huge storage capacity (Rashmi et al., 2014).

The impact of vegetation on lithological mapping was investigated using airborne multispectral data and the SAM classifier (Grebby et al. 2014), as well as on mapping lithological units from fine and moderate spatial resolution remote sensing data (Zhang \& Li. 2014).

Although the accuracy of the SAM algorithm may increase through the use hyperspectral data, difficulties remain, especially if a large-scale area is covered. None of these studies have paid any attention to improving the quality and spatial resolution of classification outputs in order to perform precise LULC classification and change detection. Thus, exploring methods to address the solution regarding SAM-based classification is urgently needed. This paper aims to modify a low-cost approach, which integrates SAM and ID algorithms by collecting training samples from highresolution images, such as from QuickBird and field observations, to monitor and analyse rapid changes in LULC in Dubai on a regional scale. The novelty of the integrated approach lies in its ability to automatically map classes and monitor changes in LULC on a regional scale in a low cost manner, which allows for LULC maps to be rapidly updated and investigating the impact of these changes on groundwater and air quality. Thereby informing future studies on environmental issues and ecological issues. The proposed approach is expected to be applicable for the classification of remote sensing data and monitoring LULC changes in arid and semiarid regions.

\section{Description of the study area}

Dubai is the second largest city in the UAE and one of the most rapidly developing cities in the world. It extends between longitude $54^{\circ} 59^{\prime}$ to $55^{\circ} 36^{\prime} 42^{\prime \prime} \mathrm{E}$ and latitude $24^{\circ} 42^{\prime} 30^{\prime \prime}$ to $55^{\circ} 16^{\prime} 59^{\prime \prime} \mathrm{N}$ (Figure 1), and is located about $150 \mathrm{~km}$ east of Abu Dhabi, the UAE capital and $7 \mathrm{~km}$ west of the Emirate of Sharjah. The Emirate of Dubai is spread over an area of about $3,885 \mathrm{~km}^{2}$, while the city is approximately $700 \mathrm{~km}^{2}$ at an elevation 5 m.a.s.l. It is divided into two by the Creek of Dubai (Khor of Dubai): the first part is known locally as Deira (north-east), while the second is known as Bur Dubai (south-west).

The climatic condition of the Emirate of Dubai is warm to sunny with average temperatures ranging from $25^{\circ} \mathrm{C}$ in the winter to $37^{\circ} \mathrm{C}$ and with humidity averaging $90 \%$ in the summer. Rainfall in Dubai is infrequent and it mostly rains during winter, with mean monthly ranges from 0.6 to $18.8 \mathrm{~mm}$ (https://services.dubaiairports.ae/dubaimet/met/climate.aspx). Agricultural activity is limited to sand dune corridors, desert and gravel plains of sand dune area and near Hatta, wherever palaeochannels (wadis) are found. Other vegetation areas (garden and parks) can be found in and around the city and along main roads. Dubai is divided into three major geomorphic regions: (i) the eastern mountains, (ii) a dune field and (ii) the western region with its coastal belt and inland sabkhas (JICA 1996) (Figure 1). The Emirate of Dubai has a variety of LC classes comprising of built-up, waterbody, farming and bare land. Among these LC classes, the two most dominant are built-up and vegetation areas. The rapid growth of Dubai has resulted in a sharp decline in desert areas and water quality, and, thus, agriculture deterioration (Elmahdy and Mohamed, 2016a,b). 


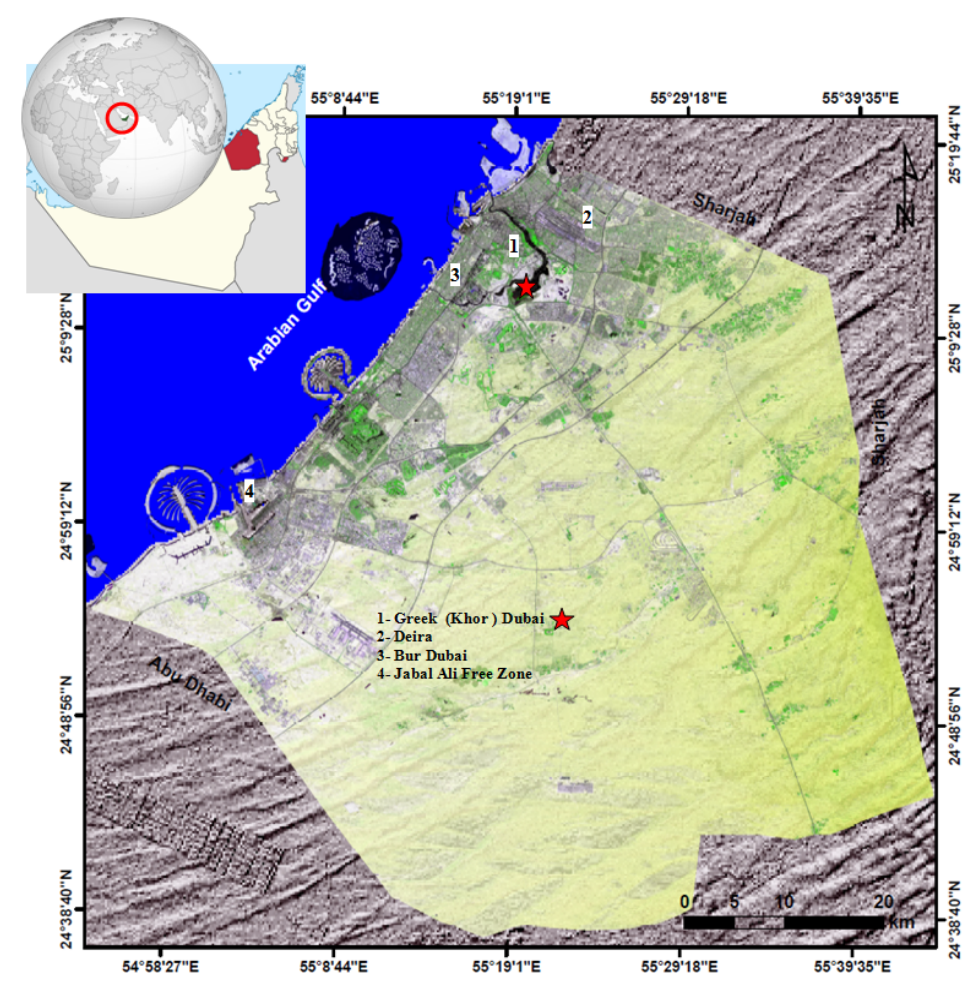

Figure 1. LULC map of Dubai Emirate as of 2015 showing the Dubai Creek (Khor of Dubai) divides the Dubai into two parts. The first part is known as Deira (NE) and Bur Dubai (SW).

\section{Materials and Methods}

Four orthorectified clouds-free multitemporal Landsat images were downloaded from the webpage of the U.S. Geological Survey (http://earthexplorer.usgs.gov) in respect of the following acquisition dates: 23 August 2000, 25 September 2005, 6 October 2010 and 14 October 2015, respectively from Landsat ETM+ and operational land imager (OLI) satellites. The bands of the four images were then stacked with excluding band 8 and thermal bands. QuickBird images with a spatial resolution of $0.6 \mathrm{~m}$, which were collected and downloaded from Google Earth (http://www.google.com/earth/download/ge/), were used to assess the accuracy of the final maps.

As a first step and to avoid any misregistration errors, all the remote sensed data were coregistered with a higher precision using 32 ground control points collected from QuickBird and field observation. The resultant images had root mean square error values of $0.33,0.39,0.45$ and 0.41 pixels, respectively. After that, the SAM classifer was feed with 320 training samples (endmembers) for LULC classes. These samples were collected from QuickBird images with a spatial resolution of $60 \mathrm{~cm}$ and validated using field observations. This type of assessment increase the accuracy of the LULC maps. 


\subsection{Image classification and accuracy assessment}

The SAM classifier suggests physically based spectral classification, which uses a $n$-D angle to match the pixels to reference spectra. The algorithm discriminates the spectral similarity between two spectra by calculating the angle between the spectra, treating them as vectors in a space with dimensionality equal to the number of bands. The SAM matches the spectral angle between the endmember spectrum vector and each pixel vector in the $n$-D space. The algorithm simplifies this geometric interpretation to n-dimensional space, determining the similarity by applying the following equation:

$$
a=\cos ^{-1}\left(\frac{\sum_{i=1}^{n b} t_{i} r_{i}}{\sqrt{\sum_{i=1}^{n b} t_{i}^{2}} \sqrt{\sum_{i=1}^{n b} r_{i}^{2}}}\right)
$$

where $n b$ is the number of bands in the image, $t$ is the pixel spectrum, $r$ is the reference spectrum and alpha is the spectral angle.

The SAM algorithm needs endmembers to be carefully collected, as this process affects the quality threshold (Kruse et al. 1993; Elmahdy 2008). As the SAM algorithm employs only the direction of the spectra, it is insensitive to the unknown gain factor, with all possible illuminations treated equally (Kruse et al. 1993). Each Landsat image was therefore, utilised to produce classification maps based on various training samples collected from QuickBird images and field observations. The obtained LULC maps were then enhanced (refine the unclassified pixels and noise in the LULC maps) by performing the following three steps:

1. Applying a $3 \times 3$ Soble filter for better boundary discrimination of LULC classes.

2. Applying majority/minority analysis with a $3 \times 3$ kernel and central pixel of 1 .

3. Applying sieve classes, using a group minimum threshold of 2 , as well as the number of neighbours and a $3 \times 3$ operator-size row of clump parameters.

4. Applying clump classes, which reduce speckles and holes in classified areas, using morphological operators followed by combining classes.

The accuracy of each enhanced LULC map was then assessed using a confusion matrix and Kappa, user's and producer's accuracy were calculated using the confusion matrix (Foody 2002). Kappa analysis, which is a discrete multivariate technique, yields a khat statistic which is a measure of the agreement or accuracy (Jensen 1996).

\subsection{Change detection}

To monitor LULC changes, a pixel-based image difference (ID) algorithm was applied to the enhanced LULC maps. The algorithm computes the number of classes and change detection type, which were applied to each pair of the enhanced LULC maps. Change detection comprised of the following four steps:

1. Performing change detection for each pair of classes by defining a different threshold: The threshold values are evenly spaced between $(-1)$ and $(+1)$ for simple difference (the initial state image is subtracted from the final state image). The positive changes (positive value) represent the first $(n / 2)$ classes, while the negative changes represent the last $(n / 2)$ classes. The no-change class $((\mathrm{n} / 2)+1)$ represents the middle class. 
2. Normalising the images (raster maps) by subtracting the image minimum.

3. The 2000 and 2005, 2005 and 2010, and 2010 and 2015 classification images were combined together, resulting in 11 changes detection classes.

The produced change detection maps consists of different colour codes, a positive change was identified when pixels took on a red colour code (final state image), while a negative change was identified when pixels took on a blue colour code (initial state image).

\section{Results}

\subsection{Image classification and analysis}

The LULC maps (Figures 2 and 3) show that the built-up area is restricted to the coastal area and on both sides of the Khor of Dubai, while the cultivated area is distributed within the desert area (such as sand dune and sand dune corridors). As seen in Figures 4 and 5, an intensive urbanization (1,356.78 $\mathrm{km}^{2}$ ) is observed along the coastal line, with a length of about $65 \mathrm{~km}$ and a width of $20 \mathrm{~km}$, which accounts for $33.73 \%$ of the total area of Dubai. In addition to intensive urbanization, areas such as gardens, parks, waterbody and offshore areas in the city of Dubai have grown extensively over the last 15 years.

In 2000, a highly concentrated built-up area was observed on both sides of the Khor of Dubai and along the coastal area. The estimated built-up area covered $96 \mathrm{~km}^{2}(2.38 \%)$, while the vegetation area (gardens and farms) was $85.27 \mathrm{~km}^{2}(2.12 \%)$ (Figure 2).

In 2005, there was a significant increase in the built-up area $\left(329.72 \mathrm{Km}^{2}\right)$, both onshore and offshore, while vegetation areas reduced from 85.27 to $37.65 \mathrm{~km}^{2}$ (Figure $2 \mathrm{~b}$ ). In the offshore area, three islands were constructed: two are in the shape of a palm tree (Palm Jumeirah and Palm Jebel Ali), while the third is in the shape of a world map, all built in shallow water at a depth of about $10-20 \mathrm{~m}$ and occupying an area of about $195 \mathrm{~km}^{2}$. In the onshore area, two expansions in urban infrastructure were monitored: the first one involved the lower sand dune areas and in the north-west to south-east direction, while the second is located in the sabkha areas in the north-east to south-west direction. In 2010 , vegetation areas increased from $37.65 \mathrm{~km}^{2}(0.48 \%)$ to $151.21 \mathrm{~km}^{2}(3.76 \%)$, while the built-up area slightly increased from $329.72 \mathrm{~km}^{2}(8.19 \%)$ to $368.53 \mathrm{~km}^{2}(9.16 \%)$ (Figures 2c). In 2015, builtup areas increased from $368.53 \mathrm{~km}^{2}(9.16 \%)$ to $624 \mathrm{~km}^{2}(15.51 \%)$, while vegetation and agricultural areas reduced slightly from $151.21 \mathrm{~km}^{2}(3.76 \%)$ to $110.38 \mathrm{~km}^{2}(2.74 \%)$ (Table 1$)$. The reason for this could be the extreme depletion in groundwater quality and quantity. Only about $18.40 \mathrm{~km}^{2}(0.45 \%)$ was covered by a waterbody (Fig. 2d).

In the 2000 and 2005 confusion matrices, the overall accuracy of the 2000 and 2005 maps was $88.1252 \%$ (kappa coefficient of 0.8464 ) and $89.0699 \%$ (kappa coefficient of 0.8583 ), respectively (Table 1). Conversely, user's accuracy and producer's accuracy for some classes were mostly higher than the total accuracy. The accuracy of the low sand dune and road areas is less than the overall accuracy.

The overall accuracy of the 2010 and 2015 maps was 90.1225\% (kappa coefficient of 0.8714) and $96.0965 \%$ (kappa coefficient of 0.9409), respectively. As shown in Table 1, the classification images of 2010 and 2015 are apparently well-mapped images. 

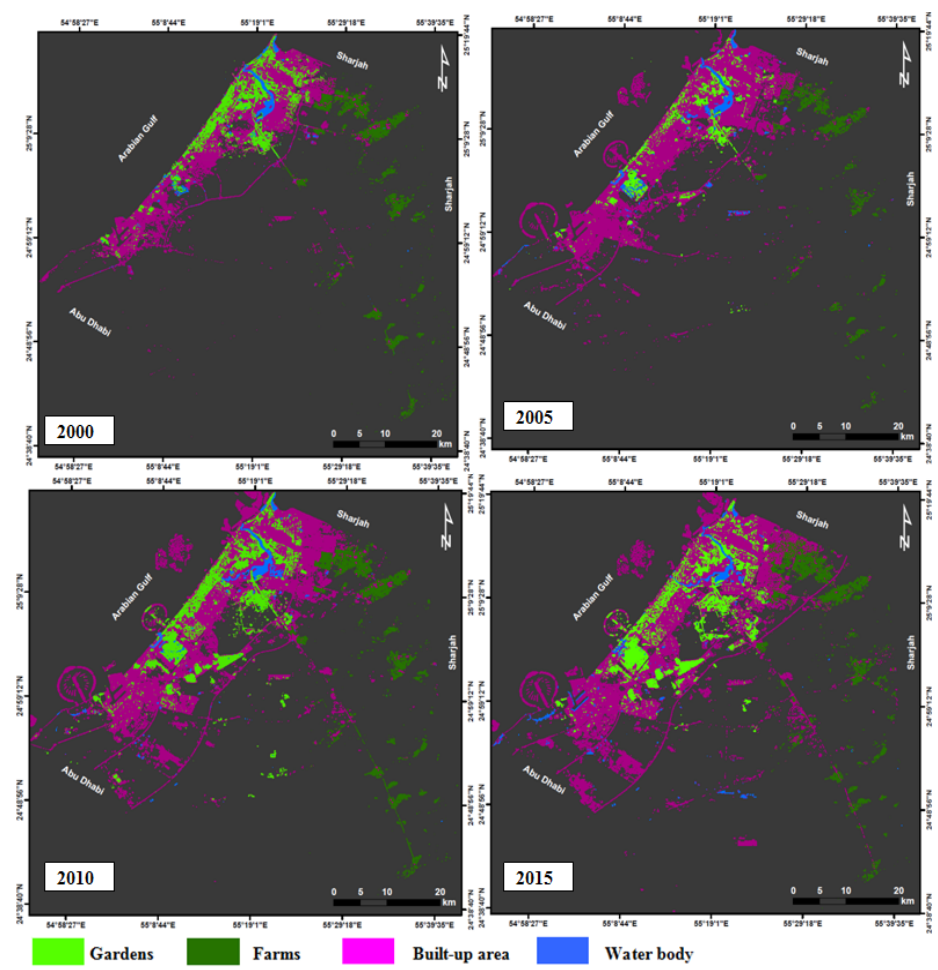

Figure 2: Maps of built-up, water and vegetation at Dubai Emirate as derived from Landsat images using SAM algorithm for the years 2000 (a), 2005(b), 2010(c), and 2015 (d).

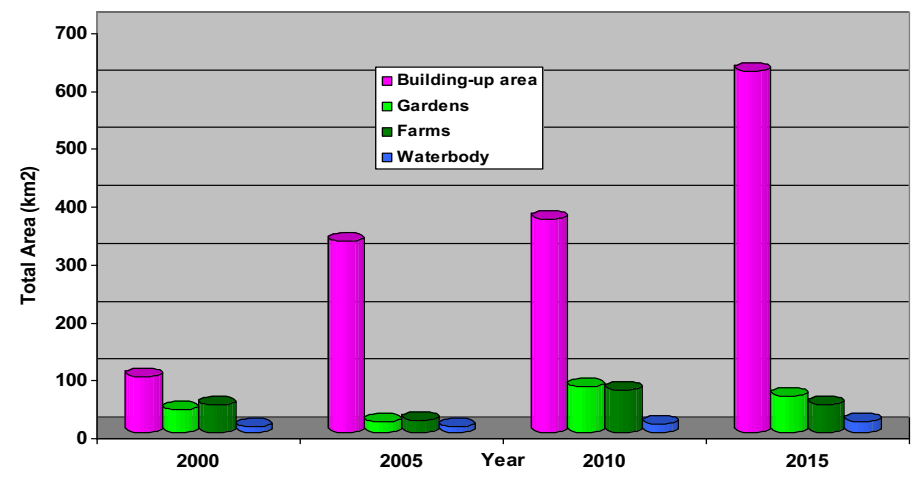

Figure 3: The graphical representation of the built-up, gardens and water body changes from 2000 to 2015

Table 1: Confusion matrix of the year 2000,2005,2010 and 2015 classification map.

\begin{tabular}{|l|l|l|}
\hline Classified map & Overall Accuracy & Kappa Coefficient \\
\hline LULC map 2000 & $88.1252 \%$ & 0.8464 \\
\hline LULC map 2005 & $89.0699 \%$ & 0.8583 \\
\hline LULC map 2010 & $90.1225 \%$ & 0.8714 \\
\hline LULC map 2015 & $96.0965 \%$ & 0.9409 \\
\hline
\end{tabular}




\subsection{Change detection analysis}

The results obtained (Figure 4) show that, from 2000 to 2005 , approximately $233.721 \mathrm{~km}^{2}(5.81 \%)$ of the Emirate of Dubai was occupied by built-up areas. The evaluation of changes in the periods $2000-$ 2005 and 2010-2015 confirmed that net vegetation area losses were more pronounced from 2000 to 2005 than from 2010 to 2015 , dropping from $47,618 \mathrm{~km}^{2}$ to $40,820 \mathrm{~km}^{2}$, respectively. Vegetation areas (gardens and farms) slightly dropped down to $47.618 \mathrm{~km}^{2}(1.17 \%)$. In fact, the period from 2010 to 2015 indicated a rate of change in built-up areas (6.35\%), while the period from 2005 to 2010 showed the highest rate of change in vegetation areas $(2.82 \%)$.
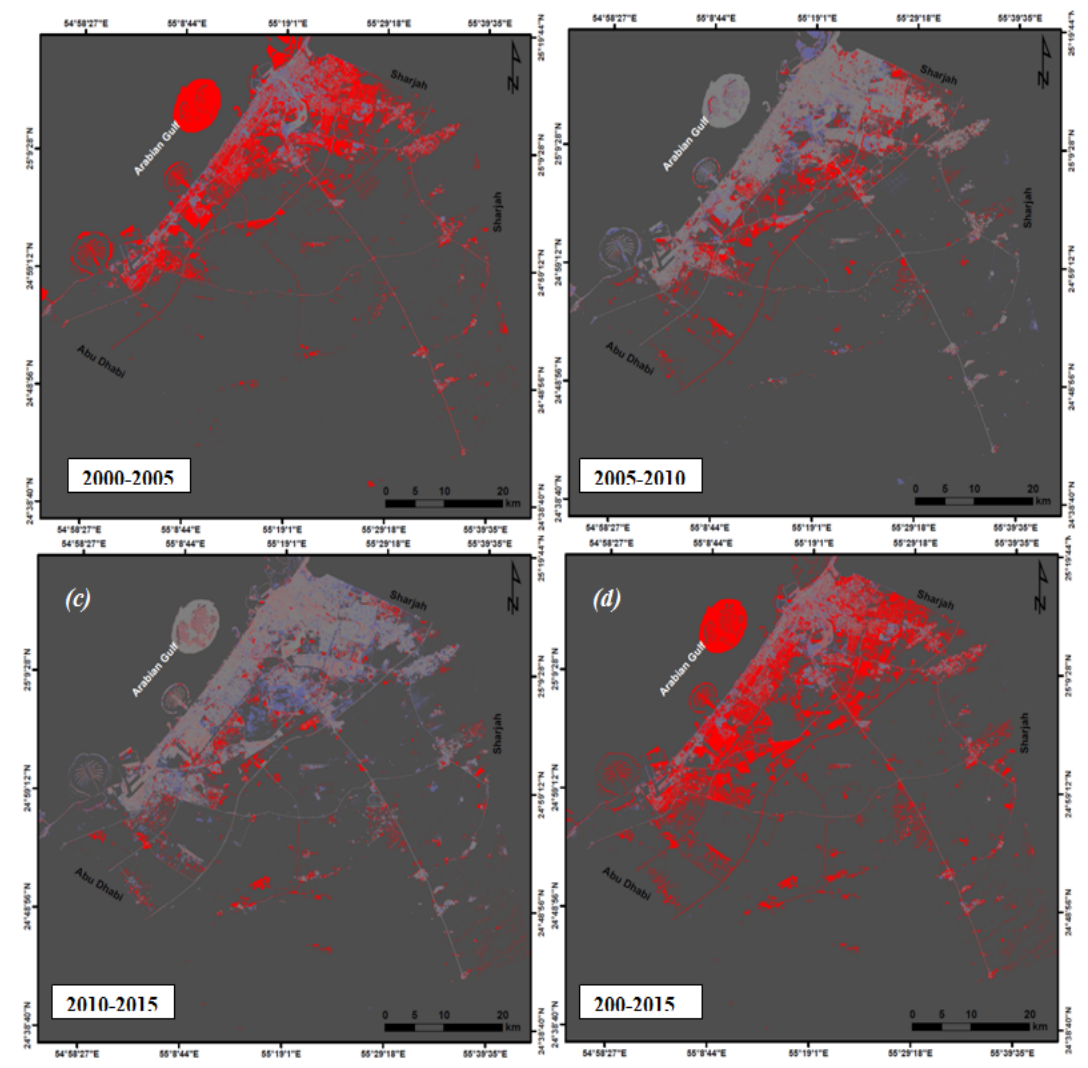

Figure 4: Change detection maps derived from a pair of classification maps using Image Difference algorithm for the years 2000-2005 (a), 2005-2010 (b), 2010-2015 (c), and 2000-2015 (d).

Positive change in built-up areas, waterbodies and road length was higher during the periods from 2000 to 2005 and from 2010 to 2015 , compared to the period from 2005 to 2010 . However, the vegetation cover loss was higher from 2000 to 2005 and from 2010 to 2015. The annual cover gain of vegetation areas increased sharply from 2005 to 2010, while the net loss of built-up areas dropped down significantly in the same period, compared to the other periods (Figure 4). The annual cover gain (positive change) in vegetation areas (gardens and farms) increased to 60.821 and $52,721 \mathrm{~km}^{2}$, respectively, for the period between 2005 and 2010 (Figure 4). 
The construction of highways (Emirates and Sheik Mohamed bin Zayed Roads), which pass through the south-eastern and south-western parts of Dubai, as well as the short distance to the coastal area and the locations of the Jebel Ali Free Zone and golf clubs, have played a major role in increasing real estate investment and attracting huge international investments and people in these areas, especially the south-western part of Dubai.

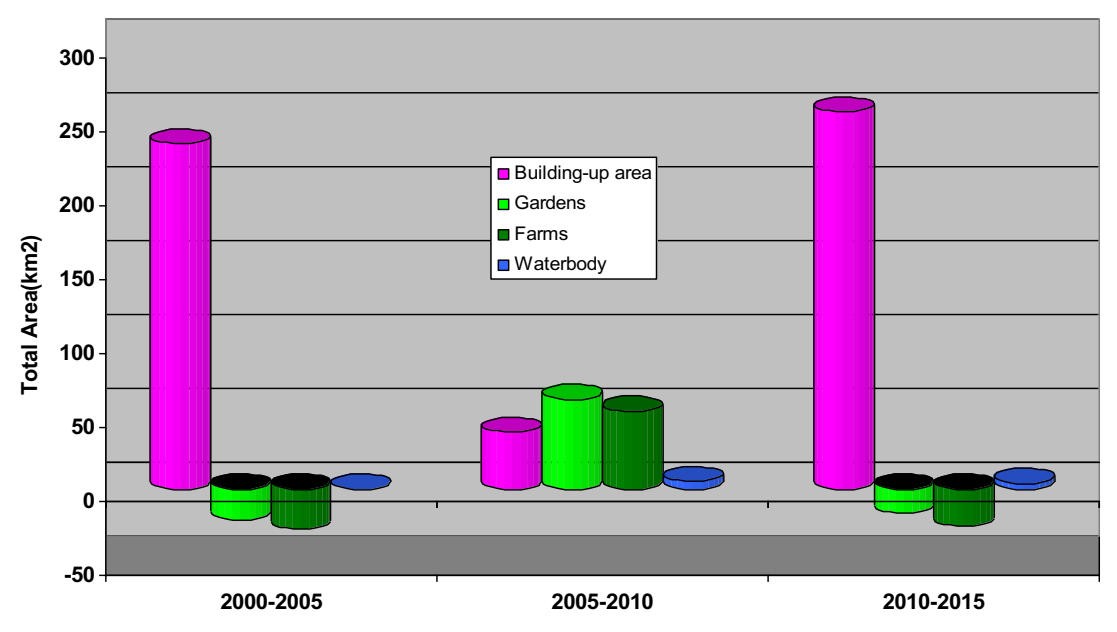

Figure 5: Changes of LU/LC classes calculated from 2000 to 2015

\section{Conclusion}

Three major modifications were made in the proposed approach for LULC classification and change detection. First, the endmembers (training sites) were collected from QuickBird images with a spatial resolution of $0.6 \mathrm{~m}$, supported with by the field observation and knowledge of the authors. Second, a set of post-classification steps, which included a Soble filter, majority/minority analysis, sieve classes and clump classes, was applied to the SAM outputs. Third, identifying a suitable threshold (between 1 and +1 ) was applied to each pair of classes. The result demonstrated that the modified and integrated approach achieved the best LULC classification and increased the precision of change detection. The results of the proposed approach provides extra geological information over a regional scale, which could not be collected during a field survey. While the newly obtained LULC maps can be used in further studies to investigate the impact of intensive urbanisation regarding groundwater, air quality and soil pollution.

\section{References}

Cho, M. A., Mathieu, R., \& Debba, P. (2009). Multiple endmember spectral-angle-mapper (SAM) analysis improves discrimination of savanna tree species. In Hyperspectral Image and Signal Processing: Evolution in Remote Sensing, 2009. WHISPERS'09. First Workshop on (pp. 14). IEEE. 
Coppin, P., Jonckheere, I., Nackaerts, K., Muys, B., \& Lambin, E. (2004). Digital change detection methods in ecosystem monitoring: A review. International Journal of Remote Sensing, 25, 1565-1596. doi:10.1080/ 0143116031000101675.

Elmahdy, S. I., \& Mohamed, M. M. (2016a). Automatic Feature Extraction Module for Change Detection in Al Ain, UAE: Analysis by Means of Multi-temporal Remote Sensing Data. Journal of the Indian Society of Remote Sensing, 44 (1), 1-10.

Elmahdy, S.I. \& Mohamed, M.M. Arab Journal Geosciences (2016b) 9: 722. doi:10.1007/s12517016-2725-y.

Elmahdy, SI. (2008). "Toward Better Mapping the Ophiolite Rocks of Northern Part of Oman Mountains using LANDSAT ETM+ and ASTER Images." International Journal of Geoinformatics 4.2.

Foody, G.M. (2002). Status of land cover classification accuracy assessment. Remote Sens. Environ., 80, 185-201.

Grebby, S., Cunningham, D., Tansey, K., \& Naden, J. (2014). The impact of vegetation on lithological mapping using airborne multispectral data: A case study for the north Troodos region, Cyprus. Remote Sensing, 6(11), 10860-10887.

Griffiths, G.H. (1988) Monitoring urban change from Landsat TM and Spot satellite imagery by image differencing. In: Proceedings of the 1988 International Geoscience and Remote Sensing Symposium, vol. 1..

Kruse, F. A., A. B. Lefkoff, J. B. Boardman, K. B. Heidebrecht, A. T. Shapiro, P. J. Barloon, and A. F. H. Goetz (1993) "The Spectral Image Processing System (SIPS) - Interactive Visualization and Analysis of Imaging spectrometer Data." Remote Sensing of Environment, v. 44, p. $145-163$.

Jensen, J. (2005). Introductory digital image processing: A remote sensing perspective (3rd ed). Englewood Cliffs, NJ: Prentice-Hall.

Lu, D., Mausel, P., Brondizio, E., \& Moran, E. (2004). Change detection techniques. International Journal of Remote Sensing, 25, 2365-2407. doi:10.1080/ 0143116031000139863.

Petropoulos, G. P., Vadrevu, K. P., \& Kalaitzidis, C. (2013). Spectral angle mapper and object-based classification combined with hyperspectral remote sensing imagery for obtaining land use/cover mapping in a Mediterranean region. Geocarto international, 28(2), 114-129.

Rashmi, S., Addamani, S., \& Ravikiran, S. (2014). Spectral Angle Mapper Algorithm for Remote Sensing Image Classification. IJISET-International Journal of Innovative Science, Engineering \& Technology, 50(4), 201-205.

Saksa, T., Uuttera, J., Kolstrom, T., Lehikoinen,M., Pekkarinen, A., Sarvi, V. (2003). Clear-cut detection in boreal forest aided by remote sensing. Scandinavian J. For. Res. 18(6), 537-546.

Zhang, X., \& Li, P. (2014). Lithological mapping from hyperspectral data by improved use of spectral angle mapper. International Journal of Applied Earth Observation and Geoinformation, 31, 95-109. 